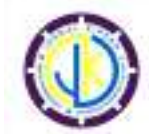

e-ISSN: 2580-6947

p-ISSN: 2354-7278

http://ojs.umrah.ac.id/index.php/kiprah/index

\title{
ANALISIS KUALITAS INSTRUMEN PENGUKURAN PEMAHAMAN KONSEP PERSAMAAN KUADRAT MELALUI TEORI TES KLASIK DAN RASCH MODEL
}

\author{
Susdelina ${ }^{1}$, Sukma Adi Perdana ${ }^{2 *}$ Febrian $^{3}$ \\ ${ }^{1,2,3}$ Universitas Maritim Raja Ali Haji, Kota Tanjungpinang, Kepulauan Riau 29115, Indonesia
}

\begin{abstract}
Abstrak
Tujuan penelitian ini adalah untuk mendeskripsikan hasil perbandingan analisis kualitas instrumen pretest pengukuran pemahaman konsep melalui pendekatan teori tes klasik dan model Rasch ditinjau dari unsur validitas, reliabilitas, tingkat kesukaran, dan daya pembeda soal. Penelitian ini merupakan penelitian kualitatif deskriptif. Data diperoleh melalui metode dokumentasi berupa 4 butir soal pretest pengukuran pemahaman konsep dan 28 lembar jawaban siswa kelas IX-3 Madrasah Tsanawiyah (MTs) Negeri Tanjungpinang dan diambil pada bulan April 2018. Selanjutnya data dianalisis melalui pendekatan teori tes klasik menggunakan bantuan program SPSS versi 23 dan model Rasch dengan software Winsteps. Hasil penelitian menunjukkan kualitas instrumen pengukuran pemahaman konsep melalui pendekatan teori tes klasik berkualitas baik dari segi validitas sedangkan melalui model Rasch belum memiliki kualitas yang baik. Reliabilitas instrumen melalui pendekatan teori tes klasik $(0,536)$ dan model Rasch $(0,71)$ termasuk kategori sedang (cukup). Berdasarkan indeks tingkat kesukaran melalui pendekatakan teori tes klasik belum memiliki kualitas yang baik, sedangkan hasil analisis melalui model Rasch menunjukkan tingkat kesukaran yang beragam yaitu mudah, sulit dan sangat sulit. Daya pembeda soal instrumen pretest pemahaman konsep melalui analisis kedua pendekatan berkategori buruk.
\end{abstract}

Kata kunci: instrumen pemahaman konsep persamaan kuadrat, teori tes klasik, model rasch

\begin{abstract}
The purpose of this study was to describe the results of the comparison of the quality analysis of instruments pretest measurement of concept understanding through the classical test theory approach and Rasch model in terms of elements of validity, reliability, level of difficulty, and distinguishing power of the problem.

This research is descriptive qualitative research. Data were obtained through documentation method in the form of 4 pretest questions on concept comprehension measurement and 28 answer sheets for students of class IX-3 of Tanjungpinang State Islamic Junior High School (MTs) and taken in April 2018. Then the data were analyzed through classical test theory approach using SPSS program version 23 and the Rasch model with Winsteps software. The results of the study showed that the quality of the instrument of understanding concept understanding through the classical test theory approach was of good quality in terms of validity while the Rasch model did not have good quality. Instrument reliability is through the classical test theory approach (0.536) and the Rasch model (0.71) including the moderate (enough) category. Based on the index of the level of difficulty through the approach of classical test theory does not have good quality, while the results of the analysis through the Rasch model shows a variety of difficulties, namely easy, difficult and very difficult. The distinguishing power of the pretest instrument of understanding the concept through the analysis of both approaches is bad.
\end{abstract}

Keywords: analysis instrument of understanding, classical test theory concept, rasch model

*Penulis Korepondensi

Email Address : $\underline{\text { ska88perdana@gmail.com }}$ 


\section{Pendahuluan}

Evaluasi hasil belajar dilakukan untuk mengukur pemahaman dan penguasaan siswa terhadap materi yang diberikan. Artinya evaluasi hasil belajar akan memberikan gambaran informasi dari masing-masing peserta didik tentang prestasi dan pencapaian kompetensi yang diperoleh dari proses (Marjiastuti dan Wahyuni, 2014). Pisca (2014: 1) menyebutkan evaluasi mempunyai peranan yang sangat penting dalam membantu pembelajar dengan mengkomunikasikan tujuan guru, meningkatkan motivasi, mendorong kebiasaan belajar yang baik dan memberikan umpan balik melalui identifikasi dari kelemahan dan kekuatan pembelajar tersendiri. Pernyataan tersebut menjelaskan bahwa evaluasi yang baik akan menghasilkan kualitas pembelajaran yang baik pula. Oleh karena itu, penting bagi pendidik untuk melaksanakan kegiatan evaluasi yang tepat dalam mengukur kemampuan akademik peserta didik. Dalam melaksanakan kegiatan evaluasi, salah satu cara yang dapat ditempuh untuk mengukur kemampuan pembelajar adalah dengan menggunakan instrumen tes atau non tes. Jenis instrumen yang umum atau sering digunakan untuk mengukur kemampuan peserta didik di sekolah adalah instrumen tes. Instrumen tes dinilai mampu mengakomodir setiap materi yang telah diajarkan oleh guru kepada siswa pada pembelajaran dalam bentuk soal-soal uraian. Soal yang digunakan dalam kegiatan evaluasi haruslah memiliki kualitas yang baik, karena soal yang memiliki kualitas baik akan dapat memberikan informasi setepat-tepatnya tentang siswa mana yang sudah atau belum menguasai materi yang telah diajarkan oleh guru.

Instrumen tes dikatakan memiliki kualiatas yang baik apabila memiliki validitas dan reliabilitas yang tinggi. Semakin tinggi nilai validitas dan reliabilitas suatu instrumen, maka akan semakin jitu data yang didapat dari suatu penelitian (Hayati \& Lailatussaadah, 2016: 170). Pernyataan tersebut didukung oleh
Tri Wahyuningsih (2015: 30) yang menjelaskan validitas dan reliabilitas merupakan faktor penting dalam penentuan tes yang baik atau tidak. Tri Wahyuningsih (2015: 31) menambahkan aspek lain yang mendukung baiknya kualitas perangkat soal adalah aspek tingkat kesukaran dan daya pembeda. Menurutnya, kedua aspek ini merupakan aspek pendukung penting yang harus disertakan dalam proses analisis agar kualitas soal dapat diketahui. Oleh karena itu uji validitas, reliabilitas, tingkat kesukaran dan daya pembeda pada instrumen tes mutlak perlu dilakukan untuk mendapatkan instrumen tes yang berkualitas.

Hal ini juga berlaku untuk seorang peneliti yang hendak melakukan penelitian khususnya pada bidang pendidikan. Dalam penelitian, instrumen tes yang akan diberikan harus memiliki nilai kualitas validitas dan reliabilitas yang tinggi agar dapat mengukur secara tepat dan akurat variabel yang menjadi sasaran penelitian. Selain validitas dan reliabiitas, tingkat kesukaran dan daya pembeda pada soal juga penting untuk diketahui agar pembuat tes dapat menggali informasi mengenai hubungan antara tingkat kemampuan peserta tes dengan tingkat kesulitan pada soal. Pada kenyataannya, kebanyakan instrumen tes masih belum diketahui kualitasnya karena jarang dilakukan uji kualitas soal. Akibatnya, terjadilah penilaian semu yang berdampak tidak terukurnya kemampuan pembelajar yang sebenarnya.

Analisis instrumen tes dalam pendidikan dapat dilakukan melalui dua pendekatan. Pendekatan pertama adalah pendekatan yang paling umum dan banyak diaplikasikan dalam pendidikan hingga saat ini terutama dalam penelitian yaitu teori tes klasik atau classical test theory (CTT). Pernyataan ini sesuai dengan pernyataan (Hidayati, 2002: 2) dalam penelitiannya yang berjudul "keakuratan hasil analisis butir menurut teori tes klasik dan teori respons butir ditinjau dari ukuran sampel", bahwa teori tes klasik atau classical test theory 
(CTT) merupakan teknik analisis yang populer dan telah digunakan secara luas pada abad ini. Teori tes klasik yang dikembangkan oleh Charles Spearman pada tahun 1904 ini bisa digunakan untuk melakukan predisksi tentang hasil dari suatu ujian (tes) (Sumintono dan Widhiarso, 2015: 14).

Pada teori tes klasik, aspek yang sangat menentukan kualitas butir soal adalah tingkat kesukaran dan daya pembeda soal. Namun, karakteristik butir soal yang dihasilkan oleh teori tes klasik inkonsisten (berubah) bergantung pada kemampuan peserta tes. Menurut Marjiastuti dan Wahyuni (2014: 95), kesalahan pengukuran pada teori tes klasik hanya dapat dicari adalah untuk kelompok bukan individu. Pendekatan yang kedua adalah pendekatan modern dengan permodelan Rasch (Rasch model) yang dicetuskan oleh Dr. Georg Rasch seorang ahli matematika dari Denmark.

Permodelan Rasch hadir untuk mengatasi kelemahan pada teori tes klasik. Permodelan Rasch memberikan pendekatan yang berbeda dalam penggunaan skor atau data mentah ujian pada konteks penilaian pendidikan. Tujuan utamanya adalah menghasilkan suatu skala pengukuran dengan interval yang sama yang nantinya dapat memberikan informasi secara akurat tentang peserta tes maupun kualitas soal yang dikerjakan. Dengan kata lain, analisis pada model Rasch akan menghasilkan informasi mengenai karakteristik butir dan siswa yang telah dibentuk menjadi metrik yang sama (Sumintono dan Widhiarso, 2015: 15).

Pada penelitian ini akan dilakukan analisis perbandingan kualitas instrumen tes pada unsur validitas, reliabilitas, tingkat kesukaran dan daya pembeda soal melalui kedua pendekatan yang telah dipaparkan di atas, yaitu teori tes klasik dan model Rasch. Instrumen tes yang digunakan pada penelitian ini adalah instrumen pretest pengukuran pemahaman konsep yang diadopsi dari instrumen penelitian yang berjudul "Efektivitas penggunaan alat peraga Blok Aljabar pada materi faktorisasi suku aljabar terhadap pemahaman konsep siswa dengan model
Pembelajaran Aktif, Inovatif, Kreatif, Efektif dan Menyenangkan (PAIKEM) di kelas IX MTs Negeri Tanjungpinang tahun 2017/2018". Analisis butir soal pada instrumen pretest pengukuran pemahaman konsep dilakukan sebagai salah satu upaya penting dalam meningkatkan kualitas alat evaluasi, mengembangkan alat evaluasi, serta menambah objektivitas suatu tes dalam mengukur kemampuan pembelajar sebagai umpan balik terhadap kegiatan pembelajaran. Selain itu hal ini menjadi sangat penting untuk mempertahankan dan meningkatkan kualitas instrumen penelitian agar terhindar dari kecacatan.

\section{Metode Penelitian}

Penelitian ini menggunakan data sekunder instrumen pretest pengukuran pemahaman konsep materi faktorisasi aljabar dilaksanakan di kelas IX-3 Madrasah Tsanawiyah (MTs) Negeri Tanjungpinang dan diambil pada bulan April 2018. Data sekunder diperoleh melalui metode dokumentasi, kemudian diperoleh dokumen tertulis berupa instrumen pretest bentuk uraian berjumlah 4 butir soal dan 28 lembar jawaban tertulis. Penelitian ini merupakan penelitian kualitatif dengan metode deskriptif. Penelitian ini dimaksudkan untuk mencari informasi dan data yang dapat digunakan untuk mendeskripsikan kualitas instrumen tes secara empiris berdasarkan unsur validitas, reliabilitas, tingkat kesukaran, dan daya pembeda soal melalui pendekatan tes teori klasik yang diolah dengan bantuan program SPSS versi 23 dan Rasch model dengan software Winsteps.

\section{Hasil dan Pembahasan Validitas}

Analisis validitas soal melalui teori tes klasik dilakukan berdasarkan uji validitas menggunakan metode korelasi product moment. Hasil perhitungan validitas soal pretest kemampuan pemahaman konsep siswa diinterpretasikan dengan patokan jika $r_{x y}>r_{\text {tabe }} l$ 
maka butir soal dikatakan valid, sebaliknya jika $\mathrm{r}_{\mathrm{xy}} \leq \mathrm{r}_{\text {tabel }}$ maka butir soal dikatakan tidak valid (Syofian, 2015:48). Sedangkan kriteria yang digunakan untuk melihat butir soal valid atau memiliki kualitas yang baik pada model Rasch adalah jika memenuhi kriteria di bawah ini (Sumintono dan Widhiarso, 2015: 71).

a. Nilai Outfit mean square (MNSQ) yang diterima: $0,5<\mathrm{MNSQ}<1,5$

b. Nilai Outfit Z-standart (ZSTD) yang diterima: $-2,0<\mathrm{ZSTD}<+2,0$

c. Nilai Point Measure Correlation (Pt Measure Corr): 0,4 < Point Measure Corr $<0,85$.

Perbandingan hasil analisis teori tes klasik dan Rasch model pada segi validitas dapat dilihat pada tabel 1 .

Tabel 1. Perbandingan Hasil Analisis Validitas Butir Soal Melalui Pendekatan Teori Tes Klasik dan Model Rasch

\begin{tabular}{|l|l|l|}
\hline $\begin{array}{l}\text { Nomor } \\
\text { Soal }\end{array}$ & $\begin{array}{l}\text { Analisis } \\
\text { validitas } \\
\text { melalui teori } \\
\text { tes klasik }\end{array}$ & $\begin{array}{l}\text { Analisis } \\
\text { validitas } \\
\text { melalui } \\
\text { model Rasch }\end{array}$ \\
\hline 1 & Tidak valid & Tidak valid \\
\hline 2 & Valid & Tidak valid \\
\hline 3 & Valid & Valid \\
\hline 4 & Valid & Tidak valid \\
\hline
\end{tabular}

Berdasarkan hasil analisis instrumen pengukuran pemahaman konsep menggunakan pendekatan teori tes klasik dengan bantuan program SPSS versi 23, diperoleh informasi bahwa soal yang dinyatakan valid sebanyak tiga soal adalah soal nomor 2, 3, dan 4, dan soal yang tidak valid ada satu soal yaitu soal nomor 1. Sedangkan pada analisis kualitas instrumen melalui model Rasch, soal yang dinyatakan valid adalah soal nomor 3, dan soal yang tidak valid sebanyak tiga soal adalah soal nomor 1,3 , dan 4.

Berdasarkan hasil analisis kualitas instrumen pretest pemahaman konsep melalui kedua pendekatan pada unsur validitas, hanya ada satu soal yang sama-sama dapat dikatakan valid atau dapat diterima pada analisis pendekatan teori tes klasik (CTT) dan model
Rasch yakni soal nomor 3, dan satu soal yang sama-sama gugur pada analisis kedua pendekatan yaitu soal nomor 4 .

\section{Reliabilitas}

Reliabilitas soal melalui teori tes klasik diukur menggunakan rumus Alpha Cronbach, hal ini dikarenakan soal yang dianalisis dalam penelitian ini berbentuk essay atau uraian, dengan interpretasi koefisien reliabilitas menurut Guilford (1956) dalam Lestari dan Yudhanegara (2017: 206).

Tabel 2. Kriteria Koefisien Korelasi Reliabilitas Instrumen

\begin{tabular}{|l|l|l|}
\hline $\begin{array}{l}\text { Koefisien } \\
\text { Korelasi }\end{array}$ & Korelasi & $\begin{array}{l}\text { Interpretasi/ } \\
\text { Reliabilitas }\end{array}$ \\
\hline $0,90 \leq \mathrm{r} \leq 1,00$ & $\begin{array}{l}\text { Sangat } \\
\text { tinggi }\end{array}$ & $\begin{array}{l}\text { Sangat tetap/ } \\
\text { sangat baik }\end{array}$ \\
\hline $0,70 \leq \mathrm{r}<0,90$ & Tinggi & Tetap/baik \\
\hline $0,40 \leq \mathrm{r}<0,70$ & Sedang & $\begin{array}{l}\text { Cukup tetap/ } \\
\text { cukup baik }\end{array}$ \\
\hline $0,20 \leq \mathrm{r}<0,40$ & Rendah & $\begin{array}{l}\text { Tidak tetap/ } \\
\text { buruk tidak }\end{array}$ \\
\hline $\mathrm{r}<0,20$ & $\begin{array}{l}\text { Sangat } \\
\text { rendah }\end{array}$ & $\begin{array}{l}\text { Sangat tetap/sangat } \\
\text { buruk }\end{array}$ \\
\hline
\end{tabular}

Sedangkan dalam model Rasch, kriteria dalam menetukan nilai Item Reliability dan Person Reliability didasarkan pada pandangan Sumintono \& Widhiarso (2015: 85) sebagai berikut:
a. <0,67: Lemah
b. 0,67-0,80: Cukup
c. 0,81-0,90: Bagus
d. 0,91-0,94: Bagus Sekali
e. >0,94: Istimewa

Hasil analisis reliabilitas instrumen pengukuran pemahaman konsep melalui kedua pendekatan diuraikan pada tabel 3 sebagai berikut. 
Tabel 3. Perbandingan Hasil Analisis Reliabilitas Insrumen Melalui Pendekatan Teori Tes Klasik dan Model Rasch.

\begin{tabular}{|c|c|c|c|c|c|}
\hline \multicolumn{2}{|c|}{$\begin{array}{c}\text { Asalisis reliabilitas melalui } \\
\text { teori tes klasik }\end{array}$} & \multicolumn{4}{|c|}{$\begin{array}{c}\text { Analisis reliabilitas melalui } \\
\text { model Rasch }\end{array}$} \\
\hline $\begin{array}{l}\text { Mlai Alpha } \\
\text { Cronbach }\end{array}$ & Kataguni & $\begin{array}{l}\text { Person } \\
\text { Reliability }\end{array}$ & Kategori & $\begin{array}{c}\text { Reas } \\
\text { Reliability }\end{array}$ & Kategon \\
\hline 0,536 & Cots & 0,03 & Lemah & 0,71 & Cukup \\
\hline
\end{tabular}

Tabel 3 memberikan informasi mengenai hasil analisis instrumen pretest pengukuran pemahaman konsep siswa pada unsur reliabilitas. Melalui pendekatan teori tes klasik (CTT) yang ditinjau dari nilai alpha cronbach, nilai reliabilitas yang diperoleh sebesar 0,536 dengan interpretasi cukup baik. Sedangkan melalui model Rasch diperoleh nilai item reliability atau reliabilitas soal sebesar 0,71 (cukup). Artinya reliabilitas soal melalui analisis teori tes klasik dan model Rasch termasuk cukup reliabel untuk digunakan pada subjek yang sama meskipun pada waktu, tempat dan oleh orang yang berbeda.

Selain reliabilitas soal, pada analisis model Rasch juga dapat diketahui nilai person reliability atau reliabilitas siswa yakni sebesar 0,03 , artinya konsistensi jawaban siswa lemah, hal ini dibuktikan dengan analisis abilitas atau kemampuan siswa berdasarkan pola repons atau jawaban siswa pada tabel skalogram, hanya 6 dari 28 siswa yang dapat menjawab soal dengan konsisten.

Berdasarkan hasil analisis kedua pendekatan, dilihat dari nilai dan kategori reliabilitas soal menunjukkan bahwa analisis melalui pendekatan teori tes klasik dan model Rasch memiliki hasil analisis yang berbeda namun termasuk pada kriteria yang sama yaitu cukup.

\section{Tingkat Kesukaran}

Pada teori pengukuran secara klasik, indeks kesukaran suatu butir soal menurut Lestari dan Yudhanegara (2017: 224) diinterpretasikan dalam kriteria sebagai berikut.

Tabel 4. Kriteria Indeks Kesukaran Instrumen

\begin{tabular}{|l|l|}
\hline IK & Interpretasi Indeks \\
\hline
\end{tabular}

\begin{tabular}{|l|l|}
\hline & Kesukaran \\
\hline $\mathrm{IK}=0,00$ & Terlalu sukar \\
\hline $0,00<\mathrm{IK} \leq 0,30$ & Sukar \\
\hline $0,30<\mathrm{IK} \leq 0,70$ & Sedang \\
\hline $0,70<\mathrm{IK} \leq 1,00$ & Mudah \\
\hline $\mathrm{IK}=1,00$ & Terlalu mudah \\
\hline
\end{tabular}

Pada model Rasch tingkat kesulitan butir soal ditinjau menurut (Sumintono dan Widhiarso, 2015: 70) yang dapat dikelompokkan menjadi empat kategori berdasarkan nilai measure yang diperoleh pada analisis model Rasch seperti berikut.

a. Nilai measure $<-1=$ item sangat mudah

b. Nilai measure -1 s.d. $0=$ item mudah

c. Nilai measure 0 s.d. $1=$ item sulit

d. Nilai measure $>1=$ item sangat sulit

Tabel 5. Perbandingan Hasil Analisis Tingkat Kesukaran Butir Melalui Pendekatan Teori Tes Klasik dan Model Rasch

\begin{tabular}{|l|l|l|l|l|l|}
\hline \multicolumn{3}{|l|}{$\begin{array}{l}\text { Analisis tingkat } \\
\text { kesukaran } \\
\text { melalui teori tes } \\
\text { klasik }\end{array}$} & \multicolumn{2}{|l|}{$\begin{array}{l}\text { Analisis tingkat } \\
\text { kesukaran melalui } \\
\text { model Rasch }\end{array}$} \\
\hline $\begin{array}{l}\text { N } \\
\text { o }\end{array}$ & IK & Kategori & $\begin{array}{l}\text { N } \\
\text { o }\end{array}$ & $\begin{array}{l}\text { Nilai } \\
\text { Measure } \\
\text { (logit) }\end{array}$ & Kategori \\
\hline 1 & 0,94 & Mudah & 1 & $-0,75$ & Mudah \\
\hline 2 & 0,76 & Mudah & 2 & 1,07 & $\begin{array}{l}\text { Sangat } \\
\text { sulit }\end{array}$ \\
\hline 3 & 0,87 & Mudah & 3 & 0,15 & Sulit \\
\hline 4 & 0,92 & Mudah & 4 & $-0,48$ & Mudah \\
\hline
\end{tabular}

Tabel 5 memberikan informasi mengenai perbandingan hasil analisis butir soal pada unsur tingkat kesukaran melalui kedua pendekatan. Hasil analisis tingkat kesukaran melalui pendekatan teori tes klasik menyatakan bahwa semua soal pada intrumen pretest pengukuran pemahaman konsep berada pada kategori mudah, dengan indeks kesukaran berturut-turut yaitu butir soal nomor 1 sebesar 0,94 , soal nomor 2 sebesar 0,76 , soal nomor 3 $(0,87)$ dan soal nomor 4 dengan indeks tingkat kesukaran 0,92 .

Selanjutnya pada analisis tingkat kesulitan butir soal berdasarkan model Rasch, 
tingkat kesulitan butir soal ditinjau berdasarkan nilai measure pada satuan logit, soal nomor 2 merupakan soal dengan kategori item sangat sulit dengan nilai measure sebesar 1,07 logit, soal nomor 3 merupakan item yang sulit karena nilai measurenya sebesar 0,15 logit. Soal dengan kategori mudah adalah soal nomor 4 dan soal nomor 1 dengan nilai measure berturut-turut $-0,48$ logit dan $-0,75$ logit.

Hasil analisis tingkat kesukaran butir soal melalui pendekatan teori tes klasik menunjukkan bahwa butir soal terdiri dari satu kelompok berdasarkan tingkat kesukarannya yaitu mudah. Sedangkan pada analisis model Rasch butir soal dikelompokkan pada tiga kategori yaitu mudah, sulit, dan sangat sulit. Selanjutnya hasil analisis pada tingkat kesukaran menunjukkan bahwa terdapat soal yang berada pada kategori yang sama melalui analisis pendekatan teori tes klasik dan model Rasch yaitu soal nomor 4 dengan kategori mudah. Selain itu terdapat juga analisis tingkat kesukaran soal yang bertolak belakang antara kedua pendekatan yaitu pada soal nomor 2 dan 3. Berdasarkan analisis melalui pendekatan teori tes klasik butir soal nomor 2 merupakan butir soal yang mudah, sedangkan menurut analisis model Rasch soal nomor 2 merupakan soal yang sangat sulit. Begitu pula dengan soal nomor 3 yang merupakan soal yang mudah menurut analisis melalui pendekatan teori tes klasik, sedangkan berdasarkan analisis model Rasch merupakan soal dengan kategori sulit.

\section{Daya Pembeda}

Daya pembeda suatu soal merupakan kemampuan soal untuk membedakan antara siswa yang memiliki tingkat kemampuan yang tinggi dengan siswa yang memiliki kemampuan yang rendah.

Selanjutnya hasil perhitungan indeks daya pembeda butir soal berdasarkan teori tes klasik beserta kriterianya disajikan pada tabel di bawah ini.

Tabel 6. Indeks Daya Beda Butir Soal Pretest Pemahaman Konsep Melalui Teori Tes Klasik

\begin{tabular}{|l|l|l|}
\hline $\begin{array}{l}\text { Nomor } \\
\text { Soal }\end{array}$ & $\begin{array}{l}\text { Indeks } \\
\text { DayaBeda }\end{array}$ & Kriteria \\
\hline 1 & 0,13 & Buruk \\
\hline 2 & 0,45 & Baik \\
\hline 3 & 0,13 & Buruk \\
\hline 4 & 0,16 & Buruk \\
\hline
\end{tabular}

Hasil analisis daya pembeda soal melalui pendekatan teori tes klasik menunjukkan bahwa soal nomor 1 dan 3 memiliki indeks daya beda yang sama yaitu sebesar 0,13 dengan kriteria buruk, soal nomor 2 dengan indeks daya beda sebesar 0,45 tergolong baik, dan soal nomor 4 masuk pada kriteria buruk dengan indeks daya beda sebesar 0,16 .

Menurut Novytasari (2014: 91) indeks daya pembeda sudah dapat dinyatakan layak apabila lebih dari 0,20 (dengan kriteria cukup). Artinya dari empat soal pretest yang telah dianalisis berdasarkan indeks daya bedanya melalui pendekatan teori tes klasik hanya ada satu soal yang merupakan soal yang layak untuk digunakan yaitu soal nomor 2 .

Berbeda dengan pendekatan teori tes klasik, pada analisis melalui model Rasch, untuk dapat membedakan kemampuan siswa yang tinggi dan rendah digunakan analisis pada tingkat abilitas individu. Selain itu dapat pula dilihat dengan cara mengidentifikasi kelompok responden berdasarkan indeks separasi responden. Menurut (Sumintono dan Widhiarso, 2015: 85) semakin besar nilai separasi maka kualitas instrumen dalam hal keseluruhan responden dan butir makin bagus, karena dapat mengidentifikasi kelompok responden dan butir. Persamaan lain untuk melihat pengelompokkan secara lebih teliti digunakan persamaan pemisahan strata $(\mathrm{H})$ :

$$
H=\frac{[(4 x \text { SEPARATION })+1]}{3}
$$

Dari nilai separasi butir sebesar 1,58 maka $\mathrm{H}=2,44$ dibulatkan menjadi 2 . Artinya 
terdapat dua kelompok butir soal yang dapat diidentifikasi dan untuk responden yang diperoleh sebesar 0,19 , maka $\mathrm{H}=0,58$ dibulatkan menjadi 1, menunjukkan bahwa instrumen pretest pengukuran pemahaman konsep belum mampu mengidentifikasi kelompok responden berdasarkan tingkat kemampuan pemahaman konsepnya. berdasarkan hasil analisis nilai separasi butir dan responden, intrumen pretest pengukuran pemahaman konsep belum cukup baik dalam mengidentifikasi kelompok aitem dan responden.

Berdasarkan analisis kedua pendekatan, terdapat kesamaan hasil analisis pada unsur daya beda soal yaitu analisis melalui teori tes klasik menyatakan sebagian besar soal berada pada kategori buruk, artinya soal tidak dapat membedakan kelompok siswa yang memiliki kemampuan yang tinggi dan rendah, begitu juga dengan analisis melalui model Rasch yang menyatakan butir soal pada instrumen pretest pemahaman konsep belum cukup baik karena belum mampu mengidentifikasi responden kedalam beberapa kelompok berdasarkan tingkat kemampuan pemahaman konsepnya.

\section{Kesimpulan}

Hasil penelitian menunjukan kualitas instrumen pengukuran pemahaman konsep melalui pendekatan teori tes klasik berkualitas baik dari segi validitas sedangkan melalui analisis model Rasch belum memiliki kualitas yang baik. Analisis reliabilitas melalui kedua pendekatan termasuk kategori sedang sebesar 0,536 melalui pendekatan teori tes klasik dan 0,71 pada model Rasch. Berdasarkan indeks tingkat kesukaran melalui pendekatakan teori tes klasik belum memiliki kualitas yang baik, sedangkan hasil analisis melalui model Rasch menunjukkan tingkat kesukaran yang beragam yaitu mudah, sulit dan sangat sulit. Pada indeks daya pembeda, sebagian besar daya pembeda soal instrumen pretest pemahaman konsep melalui analisis melalui teori tes klasik berkategori buruk. Sama halnya dengan analisis model Rasch, soal juga dinyatakan termasuk soal yang memiliki kualitas yang belum baik karena berdasarkan hasil analisis melalui nilai separasi respondennya diperoleh 1 .

Kesimpulan lain yang diperoleh adalah bahwa terdapat variabel atau parameter pada pendekatan teori tes klasik dan Rasch model yang dapat dibandingkan, artinya kedua pendekatan tersebut memiliki prinsip yang sama sebagai alat ukur properti psikometri butir soal, perbedaannya adalah analisis daya beda yang dilakukan melalui pendekatan teori tes klasik dilakukan pada perbutir soal, sedangkan pada analisis melalui model Rasch digunakan analisis berdasarkan nilai separasi responden karena pada analisis model Rasch, nilai separasi responden digunakan untuk mengidentifikasi kelompok siswa berdasarkan tingkat kemampuannya.

\section{Referensi}

Hayati, S., \& Lailatussaadah, L. (2016). Validitas dan Reliabilitas Instrumen Pengetahuan Pembelajaran Aktif, Kreatif dan Menyenangkan (Pakem) Menggunakan Model Rasch. Jurnal Ilmiah Didaktika, 16(2), 169179.

Hidayati, K. (2002). Keakuratan Hasil Analisis Butir Menurut Teori Tes Klasik dan Teori Respon Butir Ditinjau dari Ukuran Sampel, 20.

Lestari, K., \& Yudhanegara, M. (2017). Penelitian Pendidikan Matematika. Bandung: PT Refika Aditama.

Marjiastuti, K., \& Wahyuni, S. (2014). Analisis Kemampuan Peserta Didik Dengan Model Rasch.

Novytasari, Y. P. (2014). Analisis Butir Soal Pilihan Ganda Menggunakan Teori Pengukuran Klasik Pada Ulangan Umum Akhir Semester Genap Bahasa Prancis SMA Negeri 9 Yogyakarta Tahun Ajaran 2013/2014 (PhD Thesis). Universitas Negeri Yogyakarta.

Pisca, C. C. (2014). Analisis Perbandingan Kualitas Butir Soal Ujian Sekolah Bahasa Prancis SMAN 10 Yogyakarta Tahun Ajaran 2013/2014 Dilihat dari Paradigma Klasik dan Modern (PhD Thesis). Universitas Negeri Yogyakarta. 
JURNAL KIPRAH, Juni 2018; V1(1): 41-48

e-ISSN: 2580-6947

p-ISSN: 2354-7278

Sumintono, B., \& Widhiarso, W. (2015). Aplikasi pemodelan Rrasch pada Assessment Pendidikan. Trim Komunikata.

Syofian. (2015). Metode Penelitian Kuantitatif dilengkapi Perbandingan Perhitungan Manual \& SPSS. Jakarta: PRENAMEDIA GROUP.

Tri Wahyuningsih, E. (2015). Analisis Butir Soal Tes Objektif Buatan Guru Ulangan Semester Ganjil Mata Pelajaran Ekonomi Kelas X di Sma Negeri 1 Mlati Tahun Ajaran 2013/2014 (PhD Thesis). Fakultas Ekonomi. 